\title{
Dyslexia intervention to combat specific language disorder, a consequence of the economic migration
}

Katalin Tiron

Tiron Katalin - PhD Student, Psychology and Education Sciences Faculty, "Alexandru Ioan Cuza" University of Iaşi

\begin{abstract}
In the conditions of a strong economic migration, quite a few children are exposed to radical changes, which affect their development, especially in terms of communication. In the present study, we presented the case of a 7-year-old child who had a language disorder, stuttering and dyslexia. Following the intervention, based on syllabic training, stuttering, dyslexia and language were greatly reduced.
\end{abstract}

\section{KEYWORDS}

Specific language impairment, stuttering, dyslexia, intervention.

\section{INTRODUCTION}

After 1989, major economic changes took place in Romania. Many people have become unemployed and the lack of social support has forced them to look for strategies to adapt to the transition period (1). With the opening of the borders, thousands of people left Romania in search of a better life. One person left one family, others both parents. Many children were left in the care of grandparents, friends. And there is another category of children, those displaced once or even several times.
They moved with their parents, attended an educational institution there, and then they all returned. Often children are put in a position to cope in a new world, without even knowing the language well. Those who knew the Romanian language on departure, adapt more easily on return. Children born abroad, or who were very young on departure, often learn the adopted state language as a foreign language. When they return, they have great difficulties in adapting, behavioral problems, language disorders, which lead to school failure. In the present study we present the results of an 


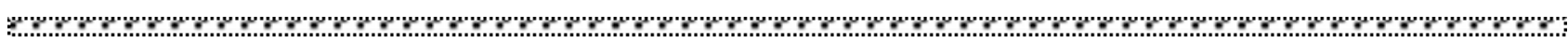

experiment performed on a 7-year-old student, who has a language disorder, stuttering and dyslexia. P. F. was born in Italy. He lived there for 4 years, then his parents moved back to Romania. When he returned to the country, he had a rather good receptive dictionary for the Italian language, for the Romanian language he is quite poor. He was enrolled in the kindergarten with extended program. Due to the fact that he did not know the Romanian language when entering kindergarten, it made it difficult for him to communicate. Not only the ignorance of the language was a difficulty, but also the multiple sounds affected in pronunciation. Interestingly, the tetism presented did not prove to be a consequence of the wrong setting, but of a very serious impairment of phonemic hearing. At the time of presentation in speech therapy, the child could not repeat two-syllable words after the speech therapist. The first word learned was "geam", which he said from the first meeting. In addition, he had developed stuttering.

Specific language disorder: is defined as persistent difficulty and language acquisition, due to hearing impairments and not due to hearing impairment or sensory abnormalities, motor dysfunction or other medical or neurological disorders and cannot be explained by intellectual disability or global retardation of development (2). It is an output disorder, which affects auditory perception, and prevents the development of appropriate learning strategies (3). The disorder is accompanied by poorly developed short-term verbal memory, poor vocabulary, and poor comprehension, especially if the interlocutor speaks quickly (4). Language is a tough process in the face of obstacles, and if one route is blocked, we usually find another. But if two or more development pathways are blocked, language will be compromised (4). In this case, there was a strong genetic component, highlighted by the fact that his brother also has a language disorder. Not having access to a developed internal dictionary, every time he tried to speak, he would get stuck and stutter. Stuttering usually sets in at an early age, just before 18 months (5). It is manifested by repetitions of sounds and syllables or monosyllabic words and induces anxiety in communication situations (2). These combined deficiencies led to a marked language disorder, which proved very difficult to compensate. The severity of the problems, accompanied by inconsistent and inconsistent parental support, led to the fact that at the beginning of first grade, P.F. still had an accentuated dyslalia, mainly due to the confusion of $\mathrm{S}-\mathrm{S}$-T, Th. The speech was intelligible, and the degree of stuttering decreased. For this reason, we expected it to develop dyslexia as well (6). Dyslexia is a disorder that leads to reading difficulties, characterized by reduced fluency (7). Fluency has three key elements: accuracy (degree of correctness), speed (the number of words reads correctly in a unit of time), and intonation (7). In order to be able to read at the appropriate speed, the child must first learn the letters and then read them in turn (decoding). Decoding ability is measured by reading non-words. After a word has been encountered several times, we recognize it and the reading becomes fluent. From this moment we can focus our attention on understanding the text (8). The process of literacy, although it seems relatively simple, is a complex process, which also involves the development of related skills, such as: knowledge of letters, phonological awareness and quick naming. These are the most important predictors for reading in a language with regular spelling (9). Phonological awareness is the ability to manipulate phonological units (10). In languages with regular spelling, the difference of dyslexic children compared to those with normal 
development is only a lower speed (11), but Romanian students are also affected by accuracy (12). Intervention: is based on PGST theory (13), according to which reading learning is influenced by the following factors: availability, consistency and granularity of language. By availability we mean that some phonological structures are not aware before learning to read (eg phoneme awareness), by consistency we mean that different sounds or spelling units can be written in several ways. This is especially reflected in the regularity of spelling. Granulation expresses the size of the spelling unit needed to learn to read. In languages with irregular spelling, such as English, it is not enough to learn the letters to be able to read. The PGST theory was developed through the Theory of syllabic connection (14). The latter highlights how the phoneme-syllable association is created. Romanian is a language with a fairly high orthographic regularity, but some sounds have several letters associated with it: cum e and â / î. Letter groups, CCV structures (consonant / consonant / vowel), CCVV, diphthongs, etc. raises special issues for children with dyslexia. In fact, they cannot make the transition from letter-to-letter decoding to word-reading. For this reason, we performed the intervention based on syllabic training. The child was exposed to each new sound to syllabic structures below the image of the corresponding word. I tried to include especially the frequent syllables and as much as possible in the initial position. Children with dyslexia have great difficulty identifying rhyme or a phonological unit in the middle of a word (15). This type of intervention has been shown to be used successfully by other researchers $(16,17,18)$.

\section{OBJECTIVES}

We wanted to see to what extent dyslexic intervention, performed by syllabic training, can reduce dyslexia in case of a language disorder.

\section{HYPOTHESIS}

H1: We assumed that with the syllabic drive a secure fixation of the letters (LK) will be achieved.

$\mathrm{H} 2$ : The syllabic training intervention will develop decoding skills (NWRA accuracy and NWRF decoding fluency).

H3: Following the intervention to combat dyslexia, the student will develop reading skills, characterized by accuracy (WRA) and fluency (WRF).

H4: At the end of the intervention, the student will present a developed phonological awareness. H5 : Following the intervention, the student will have fewer words affected by pronunciation disorder.

\section{METHOD}

Procedure: The entire WISC IV test was administered before the intervention. The score obtained IQ $=102$. He easily solved the nonverbal tests, and even in the verbal ones he had high scores. We also administered the general visual ability assessment test: developed by (19). VA $=12$, presenting spatio-visual abilities superior to his age. The language was evaluated with "Independent speech testing" developed by Vrăjmaș \& Stănică (1994). At the beginning of the intervention to combat dyslexia there were still confusions of sounds: Ş-S; J-Z; T-T. For long words with 4 or more syllables omit parts of the word. The grammatical structure of the sentences is correct, sometimes it depends on the adjective-noun agreement or on the plural of some nouns. The intervention took place during the school year 2020 2021, with tests in the second half of January, respectively in mid-July. The series of tests 
were presented in the following order: knowledge of letters, reading of words, reading of non-words, PA). We measured the time of the tasks. In the evaluation, we used, at both moments of the intervention (initial and final) DDE-2 (The Battery for Assessment of Dyslexia and Evolutive Dysorthography, Sartori et al., 1995; adapted for the Romanian population, 20). When assessing the knowledge of the letters we used Test 1 , when reading the words Test 2 , and when reading the non-words (for decoding) Test 3. The knowledge test of the letters contains 26 capital letters. Test 2 includes high frequency and uncommon words.
Phonological awareness was assessed by the deletion of syllables or sounds. For example: bamu becomes mu by removing the first syllable. For the assessment of phonological awareness (AP) we administered the Deletion subtests from "Onset Deletion Test from Battery d'evaluation du language ecrit et de ses disorders" (BELEC), by Mousty, et al. 1994, adapted for the Romanian population, 12).

\section{RESULTS}

The results obtained from the measurements are presented in Table 1 .

Table 1. The results obtained the main variables: LK- knowledge of letters; WRA-reading accuracy, WRF-reading fluency, NWRA - decoding accuracy; NWRF-decoding fluency, PA phonological awareness with the three subtests: B1, B2 and C1, WPA-words pronunciation affected

\begin{tabular}{|c|c|c|c|c|c|c|c|c|c|}
\hline & \multirow[t]{2}{*}{$L K$} & \multirow[t]{2}{*}{$W R A$} & \multirow[t]{2}{*}{$W R F$} & \multirow[t]{2}{*}{ NWRA } & \multirow[t]{2}{*}{$N W R F$} & \multicolumn{3}{|c|}{$P A$} & \multirow[t]{2}{*}{$W P A$} \\
\hline & & & & & & $B I$ & $B 2$ & $C l$ & \\
\hline Pretesting & 4 & 0 & 0 & 0 & 0 & 0 & 0 & 0 & $60 \%$ \\
\hline Testing & 26 & $80 \%$ & 8 & $85 \%$ & 6 & 16 & 16 & 10 & $80 \%$ \\
\hline
\end{tabular}

The results obtained fully support our hypotheses. The fact that the scores from the decoding samples are very close to those from the reading, shows us that PF still uses the sublexical route in reading (decoding, 12). Although at the beginning of the intervention the phonological awareness was not developed, until the end of the intervention, it reached the ceiling level. The letter learning stage is also over. In terms of language: we have an improvement in the correctness of speech, but in some words, there are still pronunciation errors. Grammatical errors are fewer, some sounds have been fixed correctly (eg J and T,).

Table 2. The results for the main variables for normal developed first-grader children

\begin{tabular}{cccccc}
\hline & $\mathrm{N}$ & Minimum & Maximum & Mean & Std. Deviation \\
\hline LK & 206 & 23 & 26 & 25.90 & .388 \\
RAN & 206 & 8.75 & 46.00 & 18.0143 & 4.63380 \\
B1 & 206 & 4 & 16 & 15.44 & 1.231 \\
B2 & 206 & 1 & 16 & 15.37 & 1.543 \\
C1 & 206 & 0 & 16 & 9.72 & 1.185 \\
WRA & 206 & 30.36 & 100.00 & 93.6720 & 9.45660 \\
WRF & 206 & .01 & .40 & .0391 & .04135 \\
NWRA & 206 & .00 & 100.00 & 84.2536 & 18.26310 \\
NWRF & 206 & .01 & 1.21 & .0626 & .09586 \\
\hline
\end{tabular}


We compared his scores with the average obtained by testing 206 students from schools in Suceava County. Although PF has improved results compared to the beginning of the intervention, we notice that they are still lower than those of normal development colleagues. The results are in agreement with other research $(21,22)$, which shows that students with dyslexia, even after an intensive intervention, have delays compared to children with normal development.

\section{DISCUSSIONS}

Dyslexia is an unexpected reading disorder considering the child's IQ. Language disorder is strongly correlated with reading difficulties (23). In the conditions of a strong economic migration, I think that we will have, unfortunately, several cases like the one presented. Even this child's brother has a language disorder, this time accompanied by behavioral problems. Intense speech therapy reduces the extent of the language disorder, but if it is severe, it probably will not resolve until school age. The aim of this study was to reveal the educational aspects specific to such cases. Dyslexia itself is a disorder, which is quite difficult to compensate, things becoming much more serious if the child is also struggling with a language disorder. Although PF has superior intelligence, pronunciation problems prevent him from achieving good school results. The intervention aimed to develop reading skills. In the conditions of an affected phonemic hearing, we considered it useful to rely on syllabic structures and especially on their visual representations (24). In addition to developing reading skills, we wanted to develop language and correct certain affected phonological representations. The results show that the student managed to develop reading skills. The scores obtained are below the average of students with normal first grade development. This is not surprising, as children with dyslexia have lower fluency and reading accuracy than their peers, even under intense intervention (25).

For the future, the intervention will have to be continued, which from now on will include more varied activities, to motivate the student. I think that motivating parents, advising, and training them so that they can help their children is very important.

\section{ACKNOWLEDGEMENTS AND DISCLOSURES}

The authors declare that they have no potential conflicts of interest to disclose

\section{REFERENCES}

1. Sârca, V. (2018) O Românie migratoare, Plecarea în străinătate a românilor între sacrificii și bunăstare, Școala Ardeleană, pp.12

2. Edition, F. (2013). Diagnostic and statistical manual of mental disorders. Am Psychiatric Assoc, 21.

3. Bishop, D. V. (1992). The underlying nature of specific language impairment. Journal of child psychology and psychiatry, 33(1), 3-66.

4. Bishop, D. V. (2006). What causes specific language impairment in children?. Current directions in psychological science, 15(5), 217-221.

5. Yairi, E., Ambrose, N. (2013). Epidemiology of stuttering: 21st century advances. Journal of fluency disorders, 38(2), 66-87.

6. Snowling, M. J. (2014). Dyslexia: A language learning impairment. Journal of the British Academy, 2(1), 43-58.

7. Hudson, R. F., Lane, H. B., Pullen, P. C. (2005). Reading fluency assessment and instruction: What, why, and how?. The Reading Teacher, 58(8), 702-714. https://doi.org/10.1598/RT.58.8.1

8. Snowling, M. J., Hulme, C. (2021). Annual Research Review: Reading disorders revisited-the critical importance of oral language. Journal of Child Psychology and Psychiatry, 62(5), 635-653. https://doi.org/10.1111/jcpp.13324 


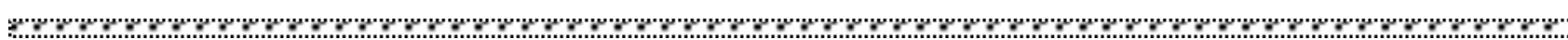

9. Tiron, K., Gherguţ, A. (2019). The predictors of dyslexia in a regular orthography. Annals of AII Cuza University. Psychology Series, 28, 67-90.

10. Anthony, J. L., Francis, D. J. (2005). Development of phonological awareness. Current directions in psychological Science, 14(5), 255-259.

11. Wimmer, H., Schurz, M. (2010). Dyslexia in regular orthographies: manifestation and causation. Dyslexia, 16(4), 283-299.

12. David, C., Roşan, A., Gavril, L. (2018). Strategie czytania rumuńskich czytelników z dysleksją w klasach podstawowych. Prima Educatione, 2, 89-98.

13. Ziegler, J. C., Goswami, U. (2005). Reading acquisition, developmental dyslexia, and skilled reading across languages: a psycholinguistic grain size theory. Psychological bulletin, 131(1), 3

14. Doignon-Camus, N., Zagar, D. (2014). The syllabic bridge: the first step in learning spelling-to-sound correspondences. Journal of Child Language, 41(5), 1147-1165.

15. Das-Smaal, E. A., Klapwijk, M. J., van der Leij, A. (1996). Training of perceptual unit processing in children with a reading disability. Cognition and Instruction, 14(2), 221-250.

16. Ecalle, J., Kleinsz, N., Magnan, A. (2013). Computer-assisted learning in young poor readers: The effect of graphosyllabic training on the development of word reading and reading comprehension. Computers in Human Behavior, 29(4), 1368-1376.

17. Müller, B., Richter, T., Karageorgos, P. (2020). Syllable-based reading improvement: Effects on word reading and reading comprehension in Grade 2. Learning and Instruction, 66, 101304.

18. Tressoldi, P. E., Vio, C., Iozzino, R. (2007). Efficacy of an intervention to improve fluency in children with developmental dyslexia in a regular orthography. Journal of learning disabilities, 40(3), 203-209.

19. Rosner, J. (1994). Helping Children Overcome Learning Difficulties. Optometry and Vision Science, 71(7), 474475 .

20. David, C., Roșan, A. (2017) Repere diagnostice bazate pe dovezi științifice în tulburările specifice de învățare

21. Zoccolotti, P., De Luca, M., Di Pace, E., Gasperini, F., Judica, A., Spinelli, D. (2005). Word length effect in early reading and in developmental dyslexia. Brain and language, 93(3), 369-373.

22. Van Bergen, E., De Jong, P. F., Plakas, A., Maassen, B., van der Leij, A. (2012). Child and parental literacy levels within families with a history of dyslexia. Journal of Child Psychology and Psychiatry, 53(1), 28-36.

23. Catts, H. W., Adlof, S. M., Hogan, T. P., Weismer, S. E. (2005). Are specific language impairment and dyslexia distinct disorders?

24. Barber, H., Vergara, M., Carreiras, M. (2004). Syllable-frequency effects in visual word recognition: evidence from ERPs. Neuroreport, 15(3), 545-548.

25. De Groot, B. J., Van den Bos, K. P., Van der Meulen, B. F., Minnaert, A. E. (2017). Rapid naming and phonemic awareness in children with or without reading disabilities and/or ADHD. Journal of Learning Disabilities, 50(2), 168179.

\section{Correspondence:}

KatalinTiron,

PhD Student, Psychology and Education Sciences Faculty, "Alexandru Ioan Cuza" University of Iaşi, katalintiron@yahoo.com

Submission: 20 aug 2021

Acceptance: 12 sep 2021 